$M H 5 M P-72-27 D$

\title{
AFNOL SYNTHESIS
}

W. T. quinlin

DEVEIOPMENT DIVISION

OCTOBER - DECEMBER 1971

SANL 900-004

For

Lawrence Livermore Laboratory

Livermore, California

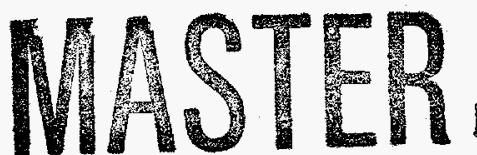

DISTRIBUTION OF THIS DOCUMENT IS UNLIMITED

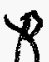

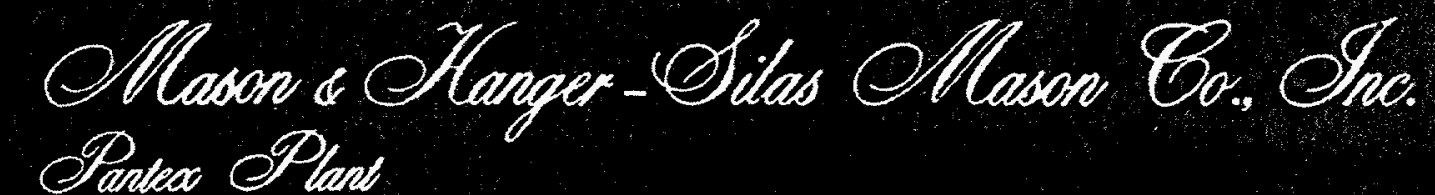

P. 0. $80 \times 647$

A.MARILLO, TEXAS 79105

806-335-1581

operated for the

ATOMIC ENERGY COMMISSION

under

U. 5. GOVERNMENT Contract DA-11-173-AMC-487 (A) 


\section{NOTICE}

This report was prepared as an account of work sponsored by the United Stutes Government. Neither the United States nor the United States Atomic Energy Commission, nor their employees, nor any of their contractors, subcontractors, or their employees, makes any warranty, express or implied, or assumes any legal liability or responsibility for the accuracy, completeness or usefulness of any information, apparatus, product or process disclosed, or represents that its use would not infringe privately-owned rights. 


\title{
AFHOL SYNTHESIS
}

\author{
w. T. Quinlin
}

DEVELOPMENT DIVISION

\section{DISCLAIMER}

This report was prepared as an account of work sponsored by an agency of the United States Government. Neither the United States Government nor any agency thereof, nor any of their employees, makes any warranty, express or implied, or assumes any legal liability or responsibility for the accuracy, completeness, or usefulness of any information, apparatus, product, or process disclosed, or represents that its use would not infringe privately owned rights. Reference herein to any specific commercial product, process, or service by trade name, trademark, manufacturer, or otherwise does not necessarily constitute or imply its endorsement, recommendation, or favoring by the United States Government or any agency thereof. The views and opinions of authors expressed herein do not necessarily state or reflect those of the United States Government or any agency thereof.

October - December 1971

SANL 900-004 



\section{DISCLAMERR}

Portions of this document may be illegible in electronic image products. Images are produced from the best available original document. 



\title{
AFIN SYITHESIS
}

\begin{abstract}
Five batches of unplasticized AFNOL, each aporoximately one pound, were sunthesized using 4,4-dinitropimelic acid as the starting material. Two $10 \mathrm{~g}$ batches were completed prior to the pound batches to assure the usability of the acid chloride. "Characterization of each of the larger batches was by differential thermaI analysis (DTA), infrared scectrophotometry (IR), and cure tests. Some characterization was also done on the commercial chemicals used in the synthesis.
\end{abstract}

\section{DISCUSSION}

The objective of the work for this quarter was to synthesize from 3 to 5 pounds of unplasticized AFNOL to be used by the pantex Formulation Facility.

The 4,4-dinitropimelic acid (DNPmA) and 2,2,8,8-tetranitro-4,6-dioxo-1,9nonanediol (DINOL) were supolied by LIL. The other reagents and solvents used for the reaction, Fig. 1, were reagent grade chemicals. The DTA's (differential thermal analyses) Figs. 2-4, and the IR's (infrared spectra), Figs. 16-18, of DNPmA, DINOL and trimethyloloropane (TMP) were determined for characterization purposes. Two small batches were run and cure samples made. The cured pieces were bubisle free and firm indicating the reagents available were of adequate purity.

\section{CHLORINATION OF 4,4-DINITROPIMELIC ACID}

The reaction was run in a 20-liter glass resin vessel heated by an ethylene glycol bath. The vessel was fitted with mechanical stirring, reflux condenser, solids addition port and nitrogen purge inlet.

Fhosphorus pentachloride, $1362 \mathrm{~g}$, was refluxed in 6 liters of carbon tetrachloride. After four hours solution was conplete. The 4,4-dinitropimelic acid, $684 \mathrm{~g}$, was added over a two-hour period at near reflux temperature. No temperature increase was observed during the addition. The foaming during addition was initially light but increased appreciably near the end. The reaction mixture was then refluxed for an additional 30 minutes. Four and one-half liters of carbon tetrachloride were then removed by reduced pressure distillation under a slight nitrogen sweep. The reaction solution was then filtered hot and the receiving vessel back-filled with nitrogen. The solution was then cooled to $10 \mathrm{C}$. The fluid was decanted from the solid mass and $500 \mathrm{ml}$ of petroleun ether added. The solids were stirred into the petroleum ether and the slurry filtered. The washing procedure was then repeated three times with $1000 \mathrm{ml}$ portions of petroleum ether. The solids were then recrystallized from 3 liters of carbon tetrachloride. A yellow layer of oil formed during the cooling, this layer was processed separately. The solids were filtered out and washed with petroleum ether. 
The combined yield of the four batches was $1409 \mathrm{~g}(44.98$ of theoretical). The DTA's, Figs. 5-8, and IR's, Figs. 19-22, of each of the four batches were determined. The chlorinated product was stored under a nitrogen atmosphere at a reduced pressure.

The second phase of the synthesis included two esterifications: condensation of the 4,4-dinitropimeloyl chloride (DNPMCl) with DINOL followed by the reaction of the above product with TMP. " Two nominal $10 \mathrm{~g}$ and five nominal one-pound" batches were synthesized.

\section{ESTERIFICATION OF DNPMCI WITH DINOL}

The reaction was run in a 3-liter resin flask with a liquid jacket for heating. The flask was fitted with an air stirrer, a condenser and a nitrogen purge. A delivery tube was mounted on top of the condenser to bring the evolved hydrogen chloride gas to a water trap. The reaction was heated to $68 \mathrm{C}$ by circulating water through the vessel jacket.

The DINOL hydrate, $202 \mathrm{~g}$, was added to the vessel under a nitrogen sweep. When melted the stirring was turned on and the water of hydration was allowed to bypass the condenser. After 150 minutes the $241.2 \mathrm{~g}$ of DNPmCl was added to the vessel. The stirring was continued and the nitrogen purge left on. Some foaming was observed. After 140 minutes titration of the hydrogen chloride evolved indicated the reaction to be $99.8 \%$ complete.

\section{ESTERIFICATION OF DINOL-DNPMCI COPOLYMER WITH TMP}

The reaction was run in the same setup as the first esterification. Ethylene dichloride $(500 \mathrm{ml})$ and $42.8 \mathrm{~g}$ of TMP were added to the reaction flask containing the previous product. The stirrer was turned on and $74 \mathrm{C}$ water was circulated through the jacket for heating. After 210 minutes titration of the hydrogen chloride evolved indicated the reaction to be $60.5 \%$ complete and to be proceeding at a rate of less than $0.01 \%$ per minute. The product from this reaction was filtered hot to remove solid impurities and stored in an air tight container.

Four of the batches went essentially as described above. The fifth one did not. Figs 10 and 11 show the percent completion of a typical batch as well as the fifth batch esterifications with respect to time. The first esterification of the fifth batch reached only $80 \%$ of completion after 24 hours, while batches 1 through 4 approached 100\%. The reason for the incompleteness is unknown. The second esterification on the fifth batch exceeded the expected completion percentage by $33 \%$. The product from this reaction was considerably less soluble in ethylene dichloride and in FEFO [bis (2,2-dinitro-2-fluoroethyl)formal] than were the other batches. The insolubility may have occurred from cross-iinking taking place due to excess acid chloride groups remaining from the first esterification reacting with more of the hydroxyl functional groups on TMP than has been normally encountered. 
Samples from each of the five batches were taken upon completion of the second esterification. Characterization of these batches was done by DTA, Figs. 11-15, and IR, Figs. 23-27.

The product from the five batches in an approximately equal volume of ethylene dichloride was delivered to the Pantex Formulation Facility.

\section{FUTURE WORK; COMMENTS; CONCLUSIONS}

Sufficient materials are presently on hand to make several more pounds of unplasticized AFNOL. This will be done upon request of the Formulation Facility. In the interim some small scale work will be done on developing a better procedure to remove impurities from the crude DNPmCl.

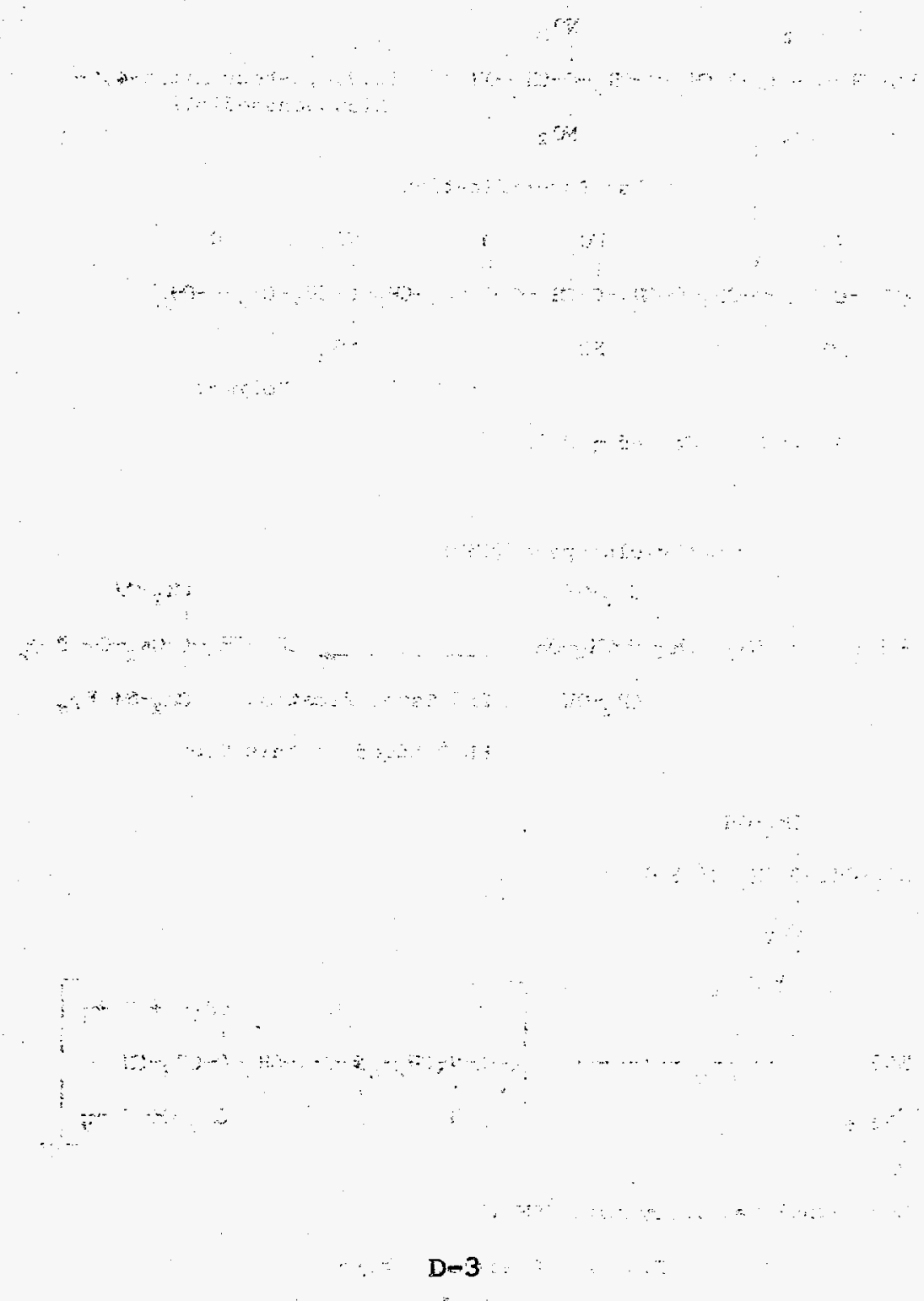




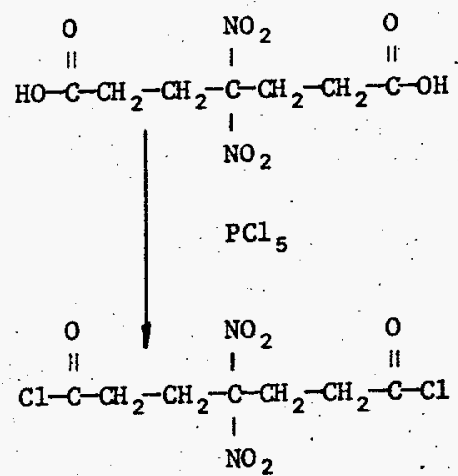<smiles></smiles>

(2,2-Dinitropimelic Acid)

(The Acid Chloride of 2,2-Dinitropimelic Acid)

$(2,2,8,8-T e t r a n i t r o-4,6-$ Dioxononanediol

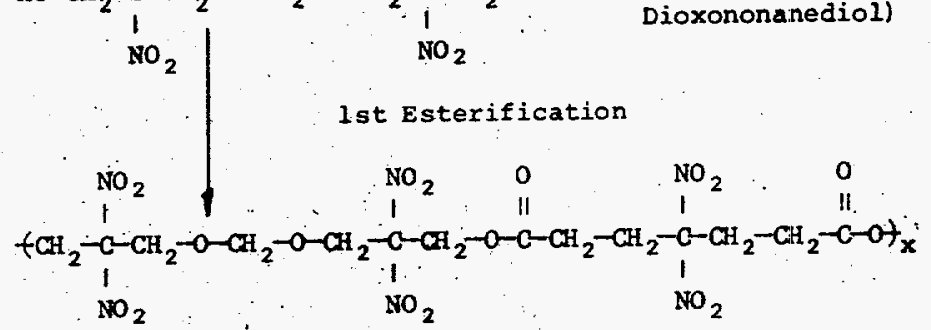

Polymex

Above Unit Called $f P t_{x}$
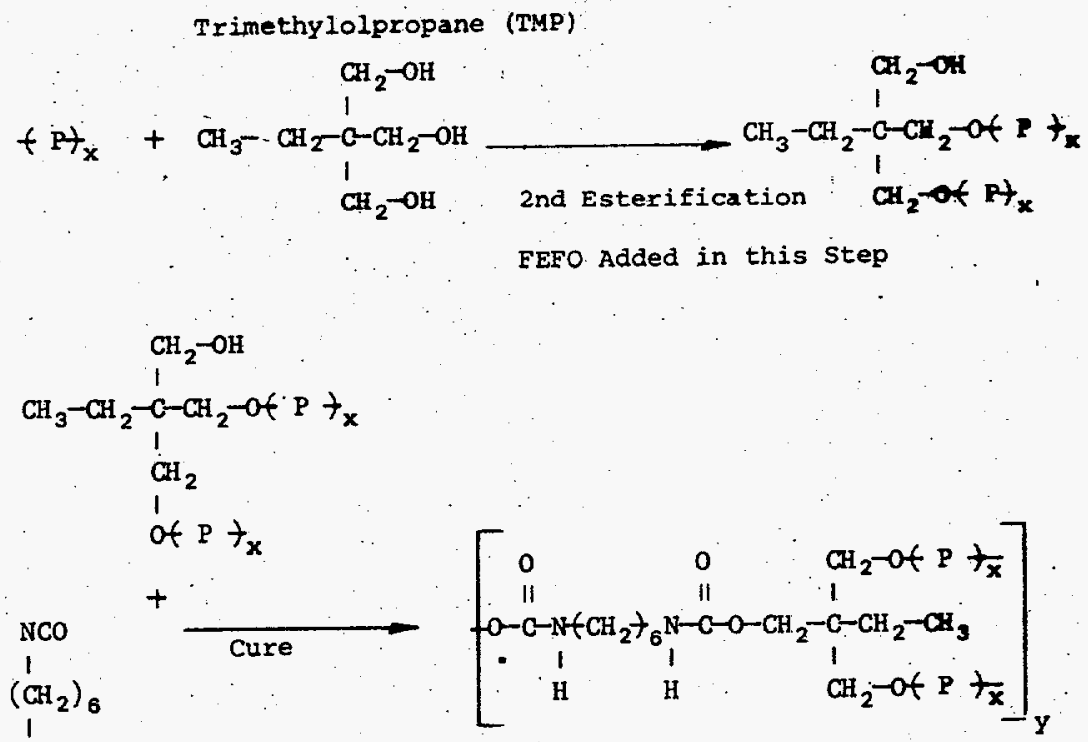

NCO

Hexamethylenedisocyanate (HMDI)

Fig. 1. Reaction Scheme 


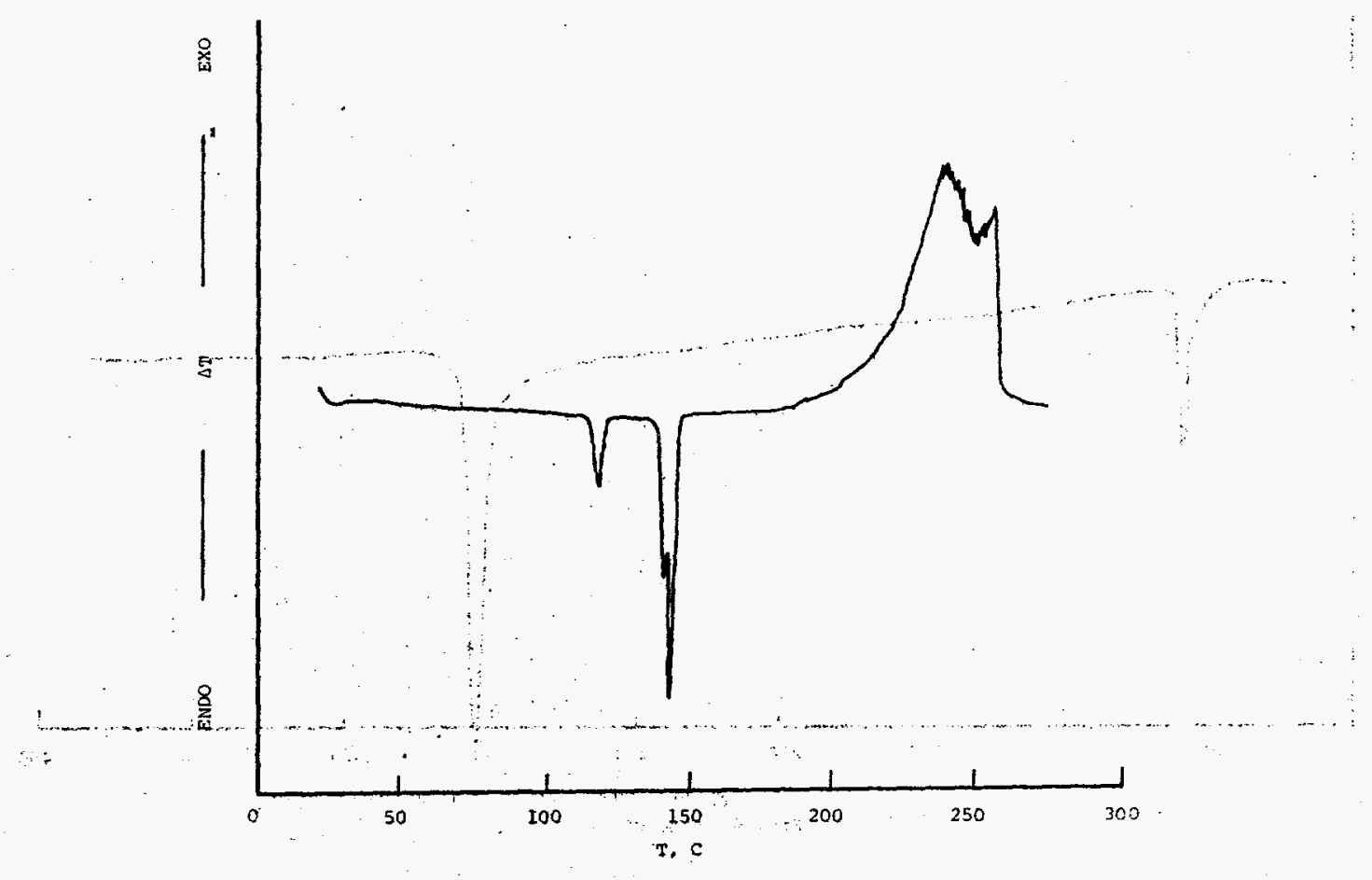

FIg. 2. DTA-DNPOH

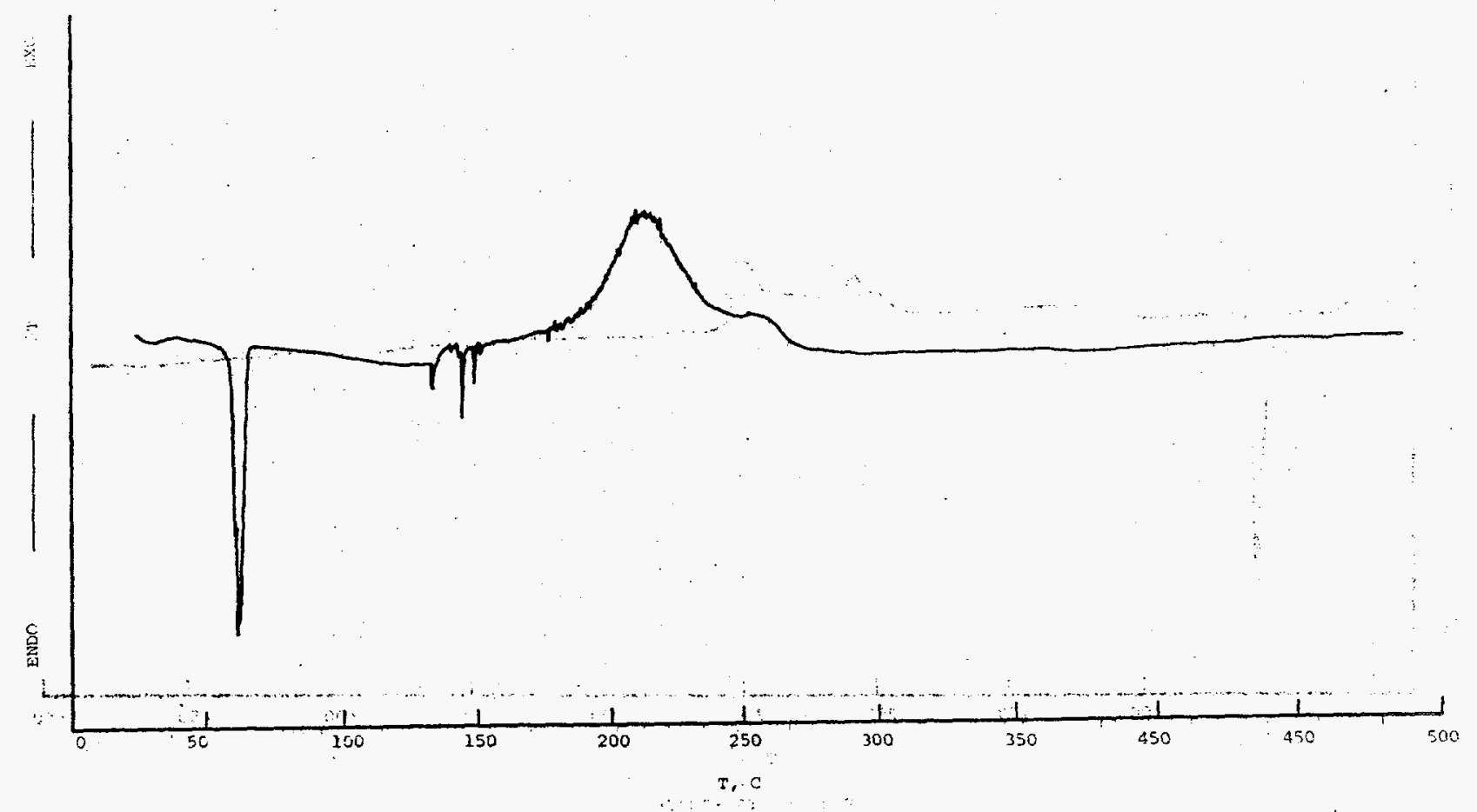

Fig, 3. DTA-DINOL

D-5 

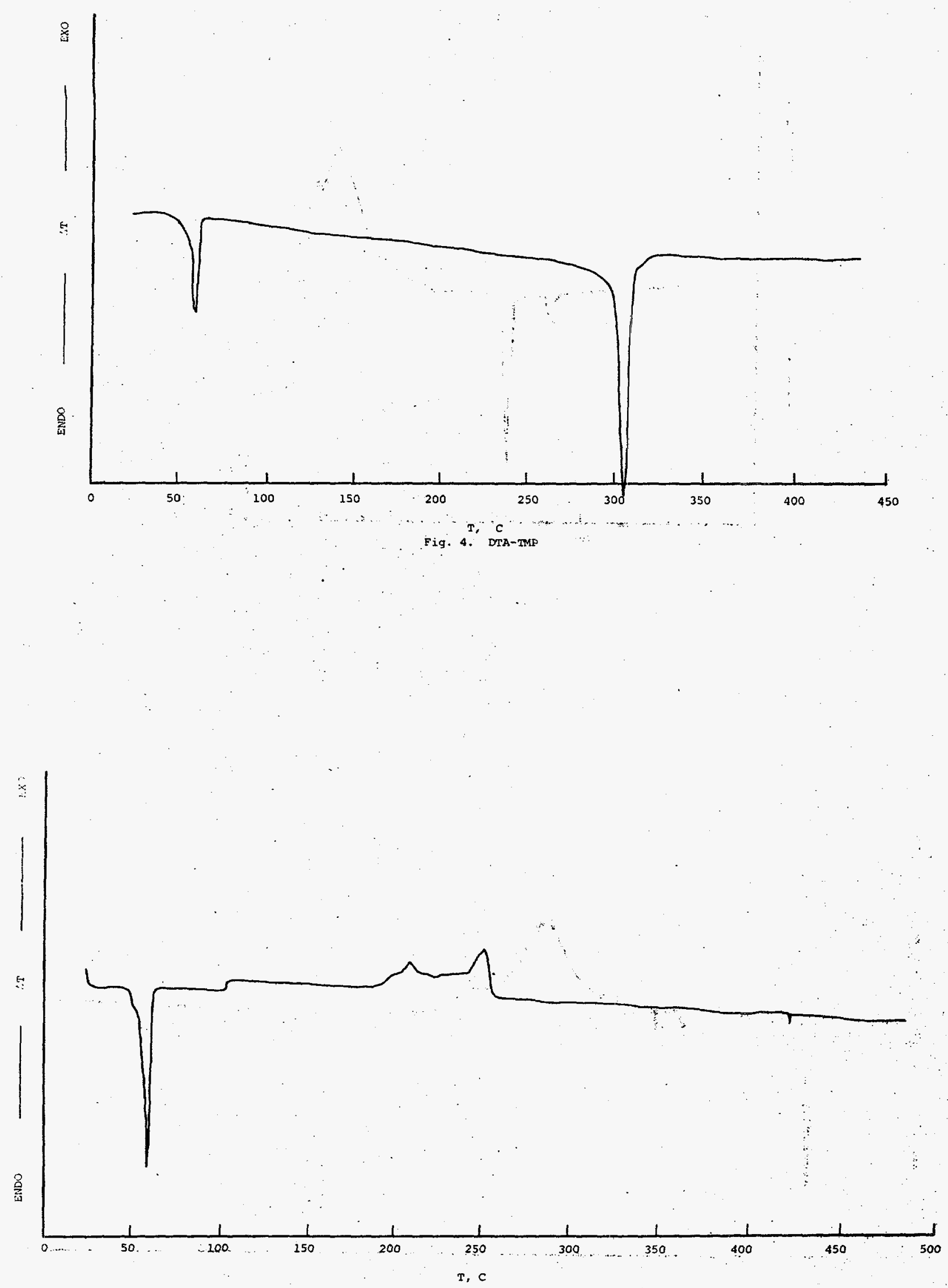

Fig. 5. DMA-DNPC1

Batch \#1 

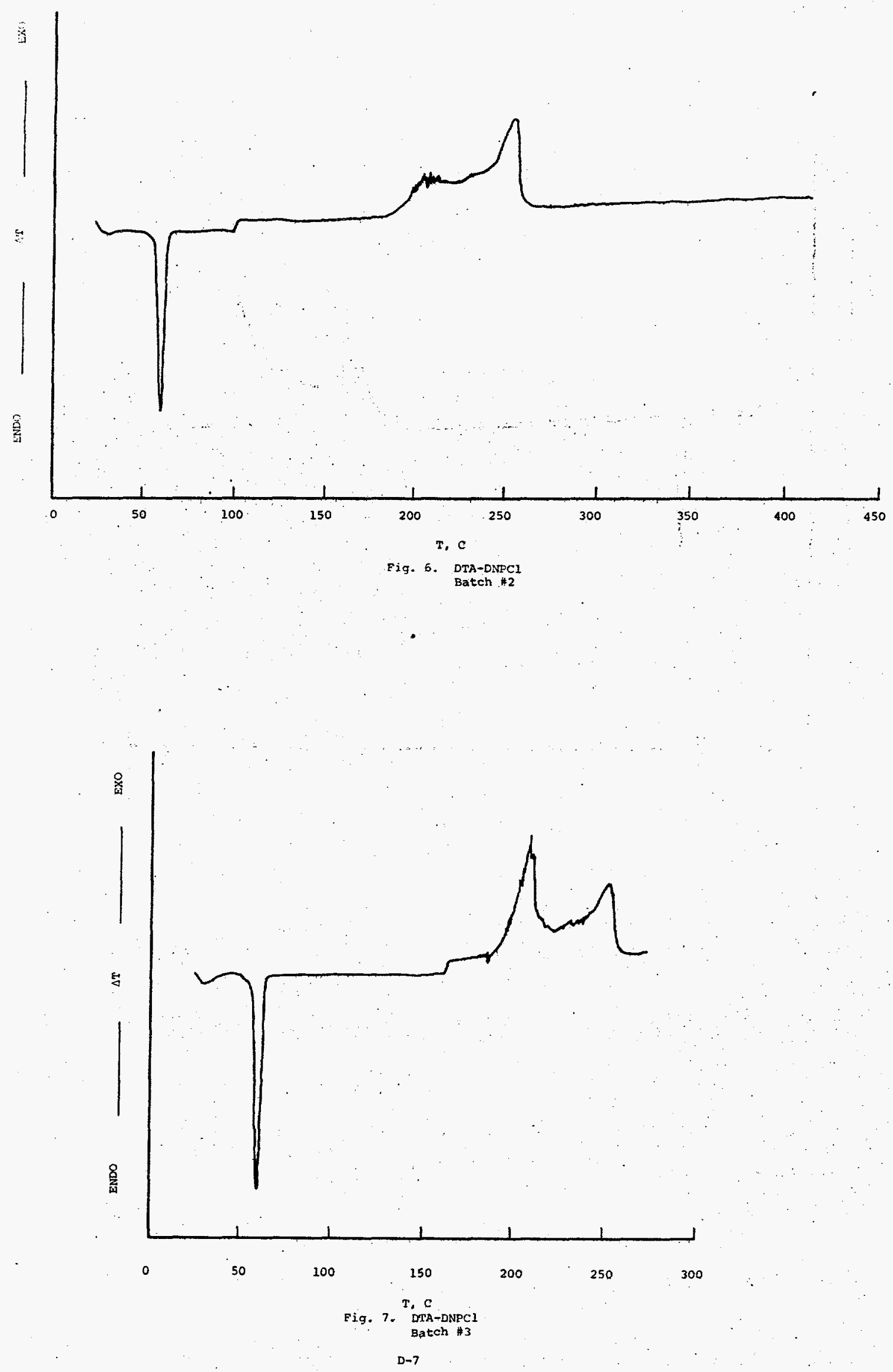


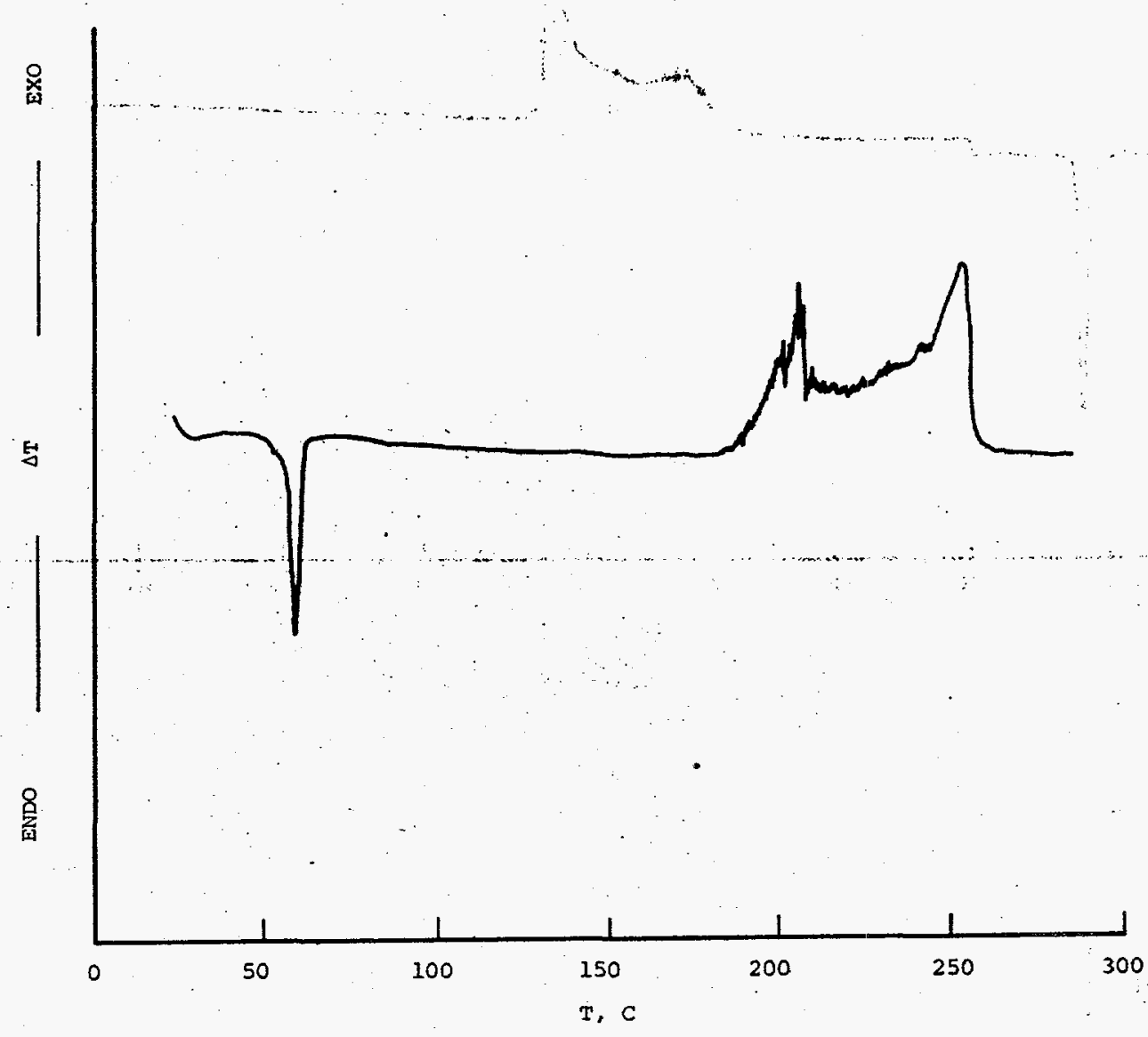

Fig. 8. DTA-DNPCI

Batch \#4 

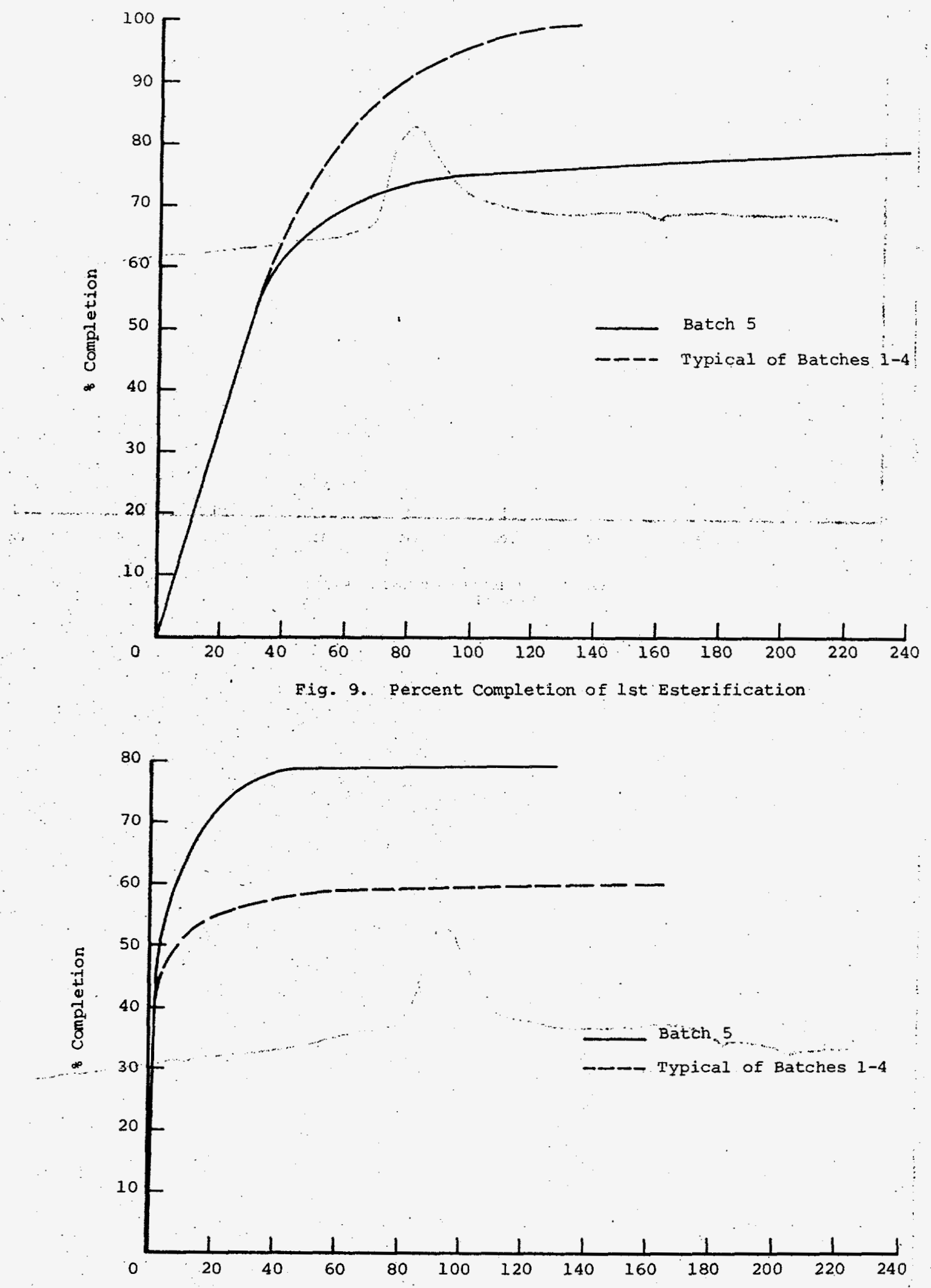

Fig. 10. Percent Completion of 2nd Esterification 


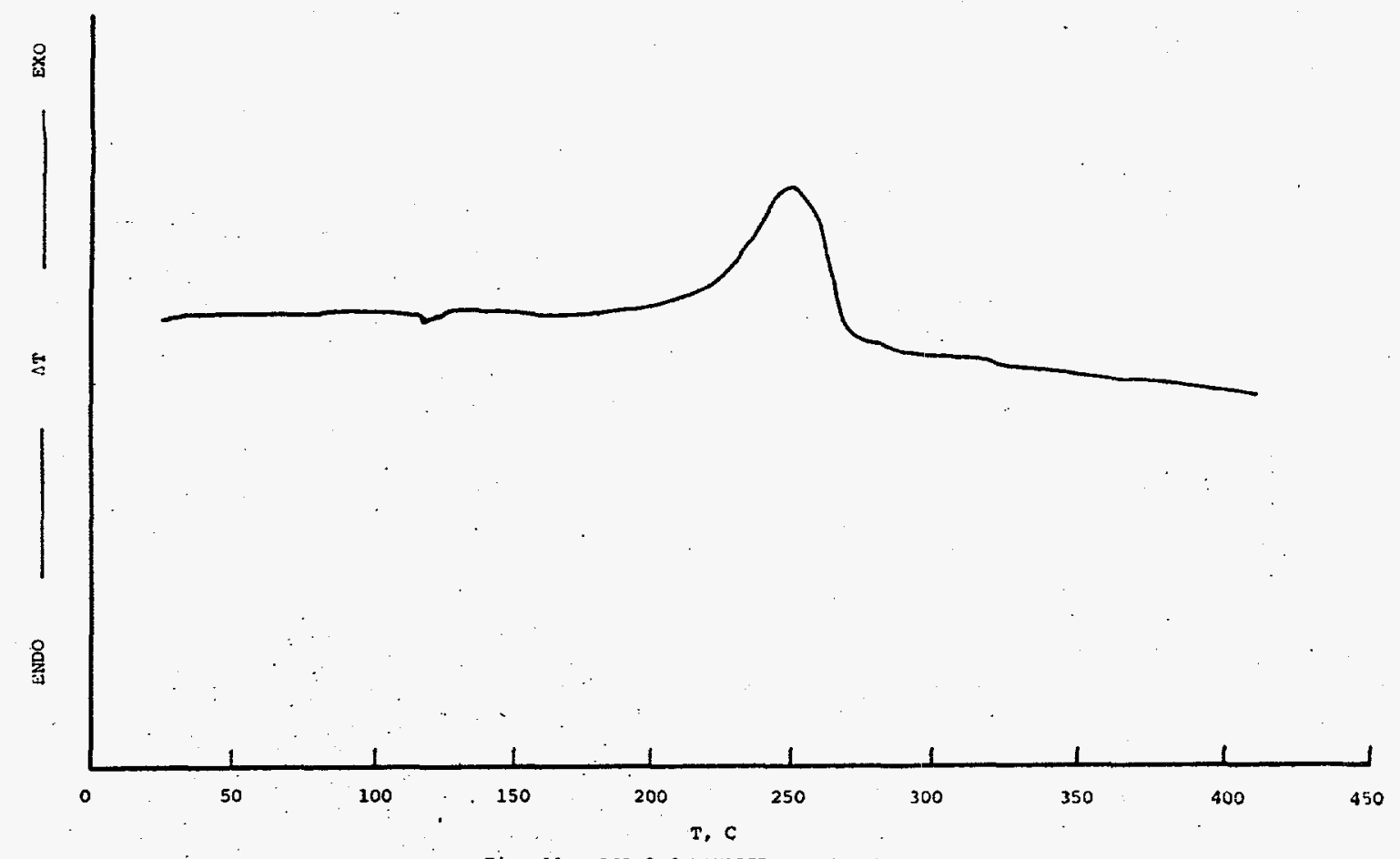

Fig. 11. DTA-2nd ESTERIFICATION PRODUCT

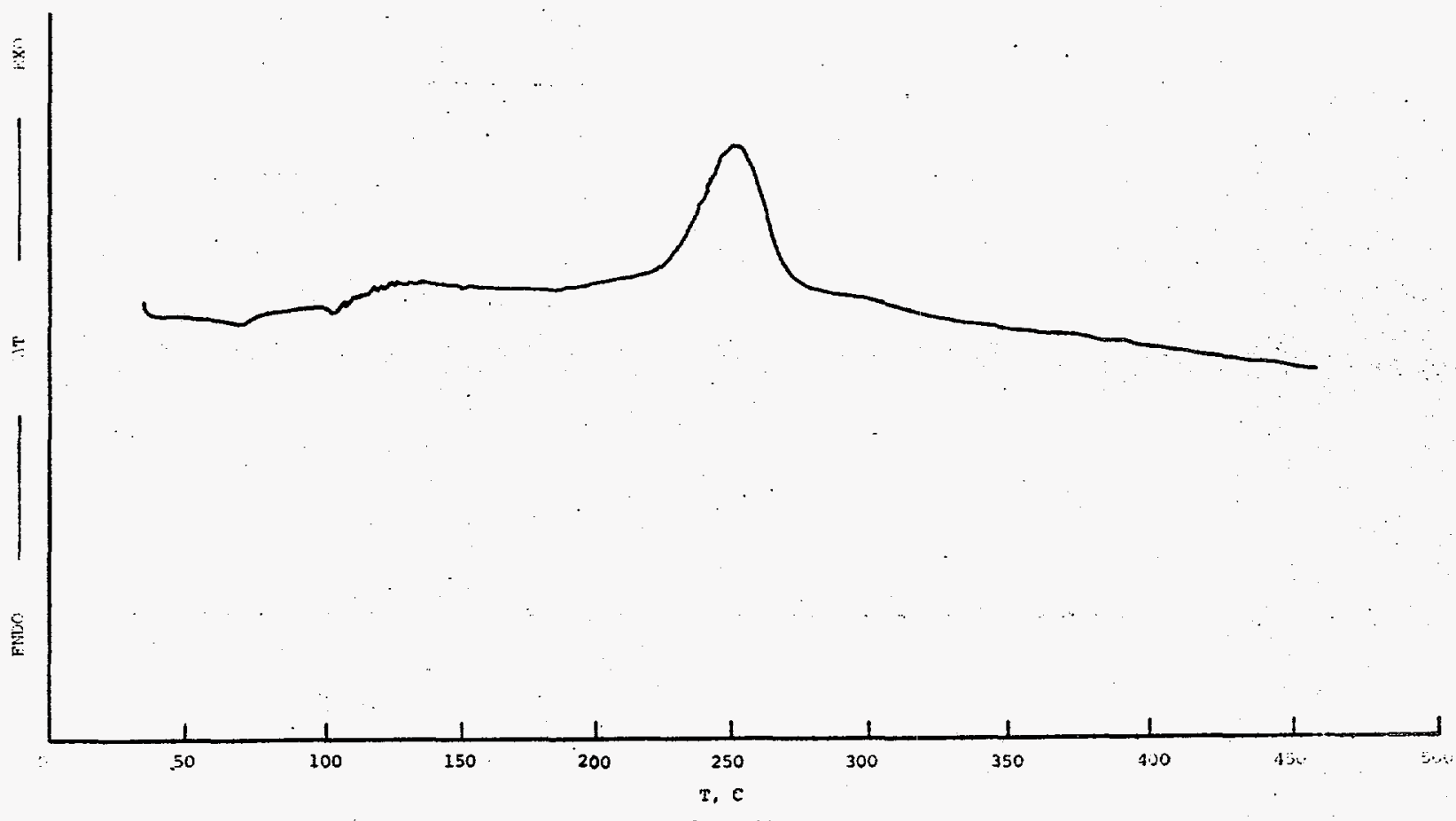

Fig. 12. DTA-2nd ESTERIFICAT ION PROULL

Batch \#2

D-10 


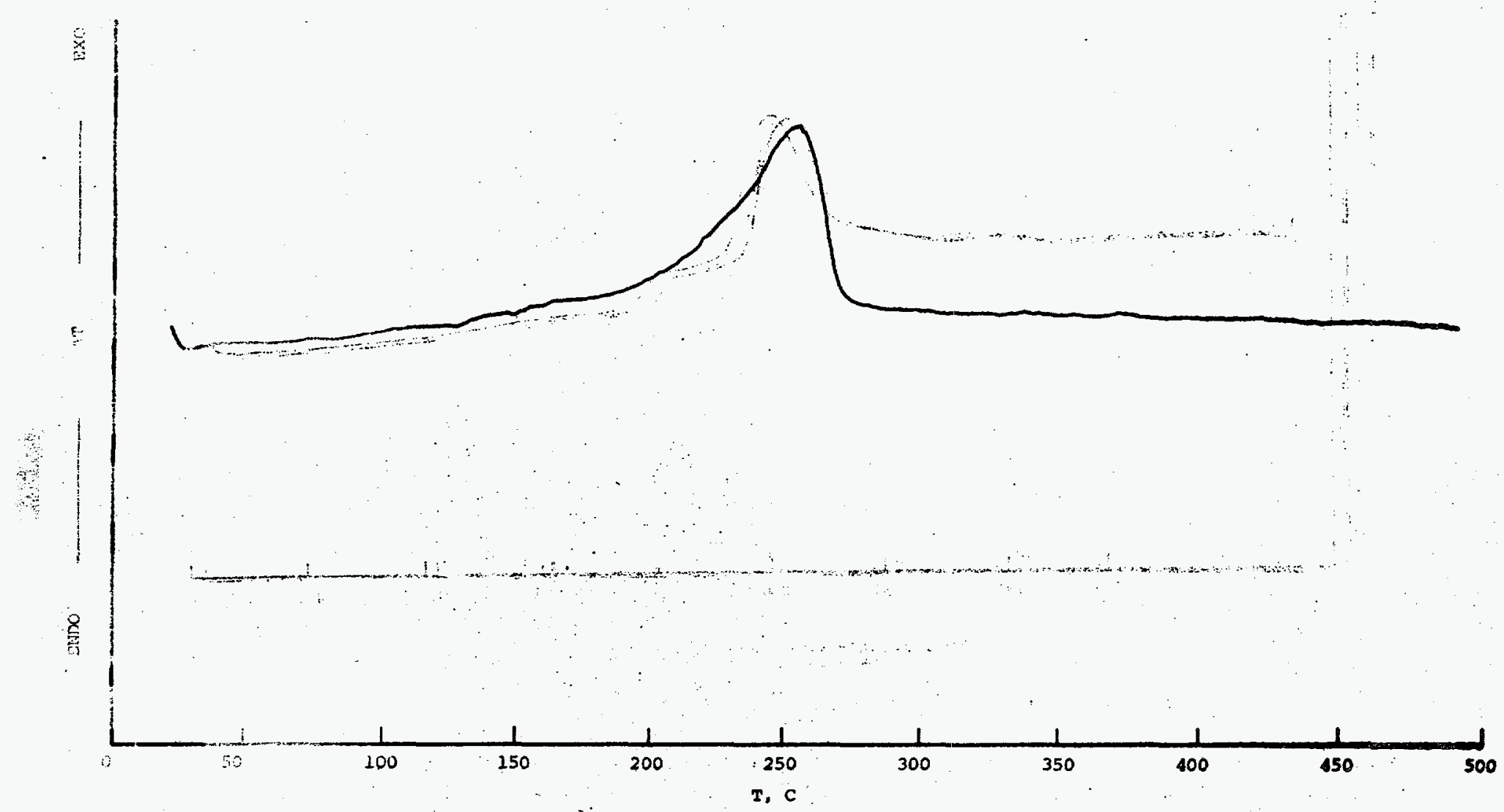

Fig. 15. DTA-2nd ESTERIFICATION PRODUCT Batch 5 



Fig. 17. IR-Spectra-DINOL KBr Pellet 

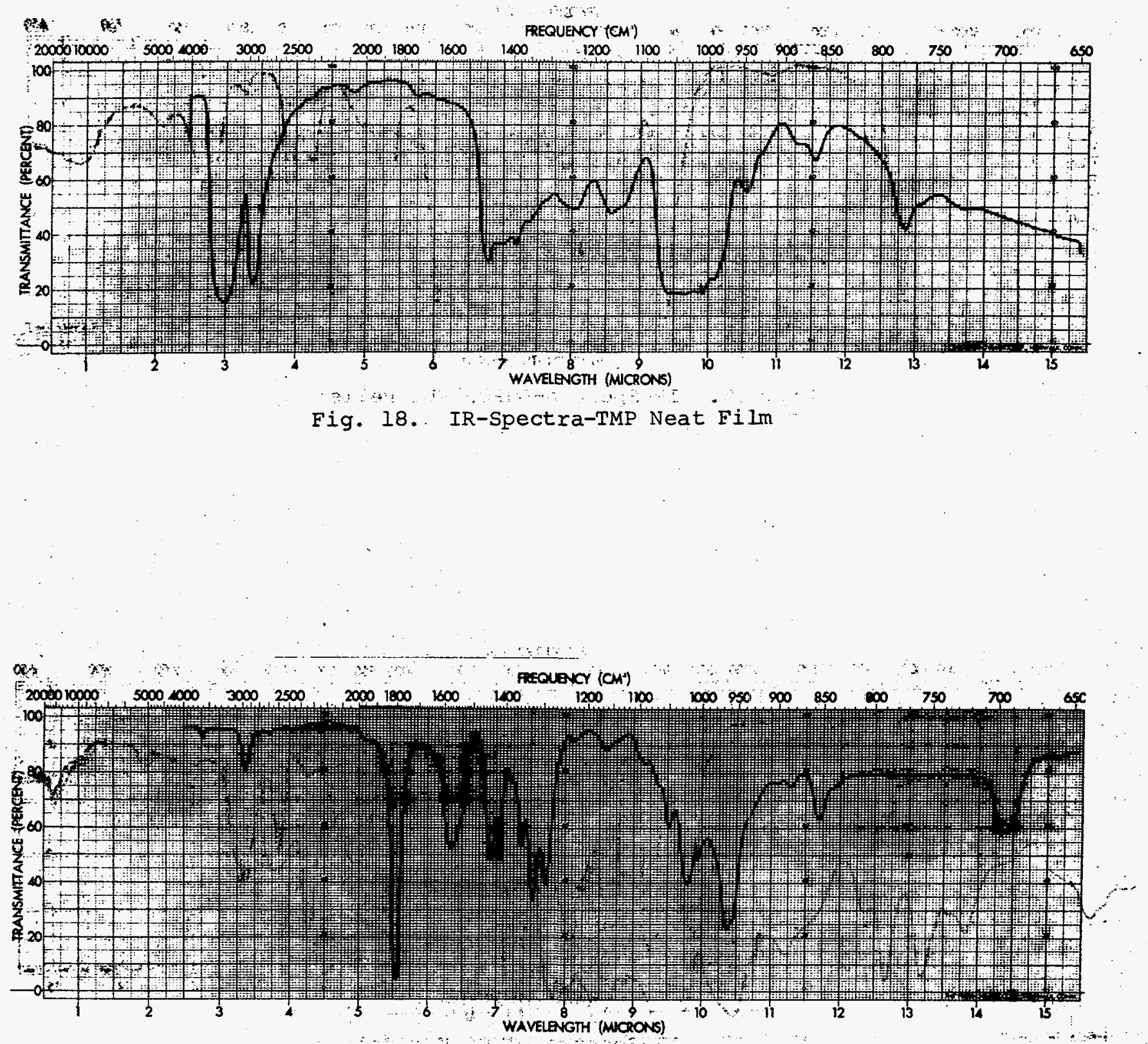

Fig. 19. IR-DNPCl-CCl 4 solution Batch No. 1 


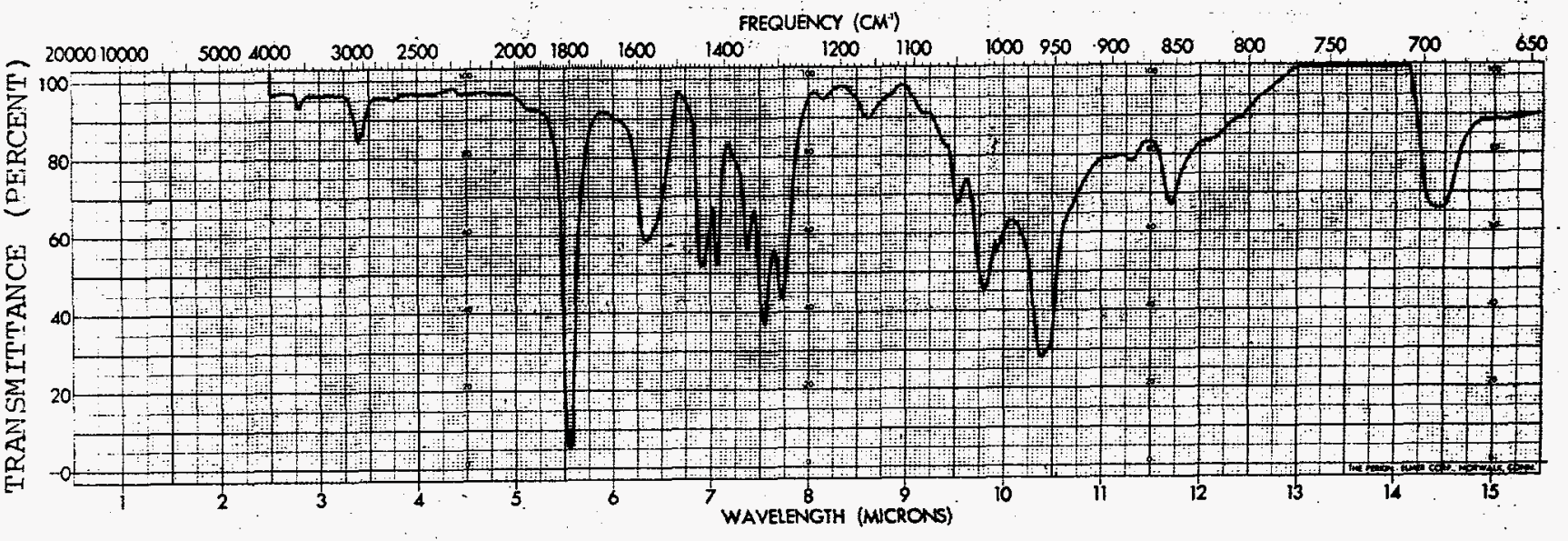

Fig. 20. IR-DNPCI-CCl $1_{4}$ Solution Batch No. 7

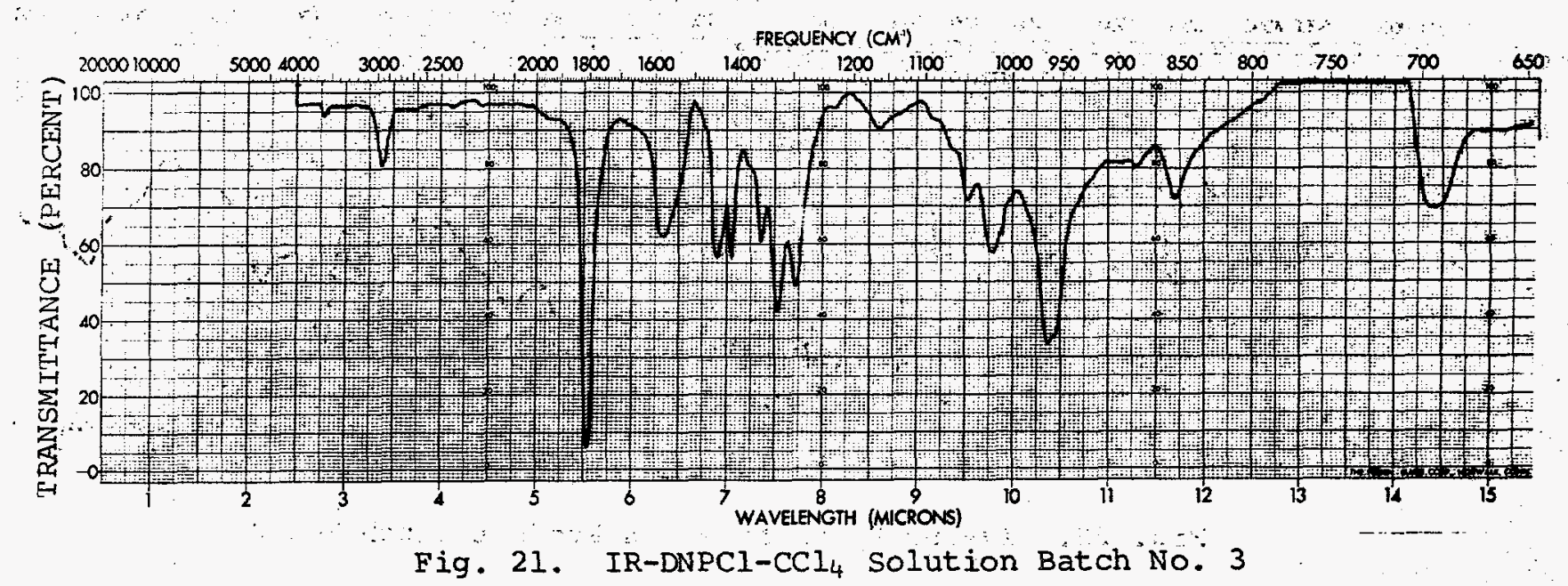




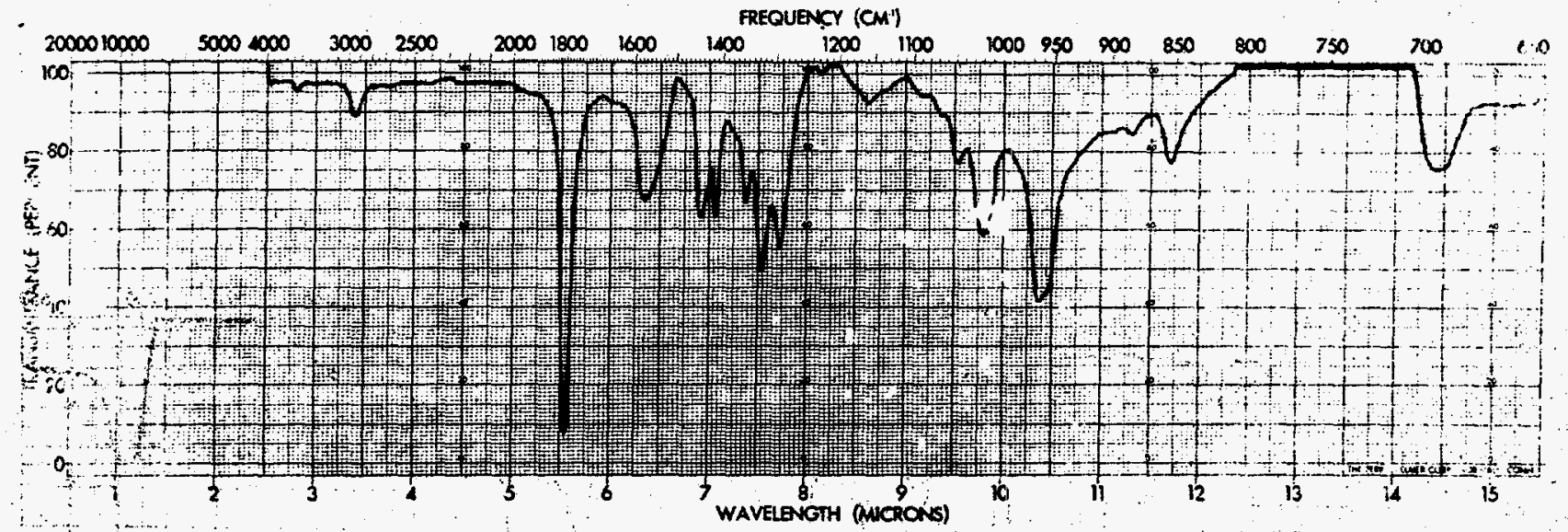

Fig. 22. IR-DNPCl-CCl 4 Solution Batch No. 4

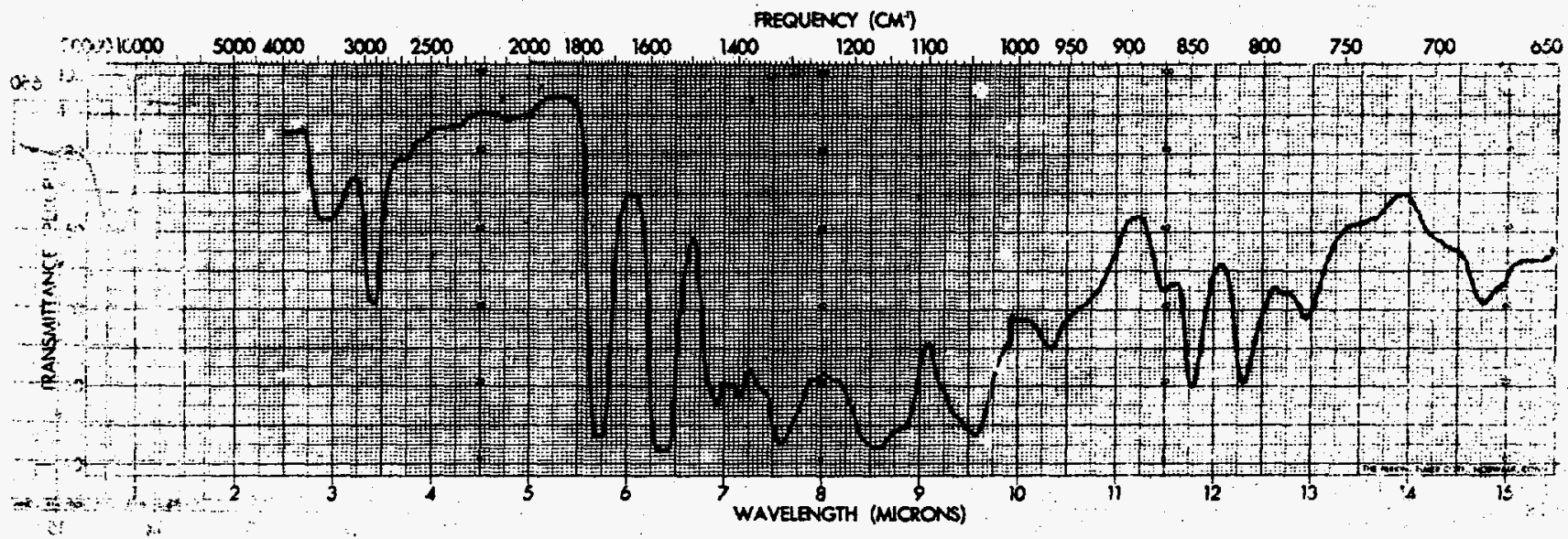

Fig. 23. IR-2nd Esterification Product Batch No. 1 


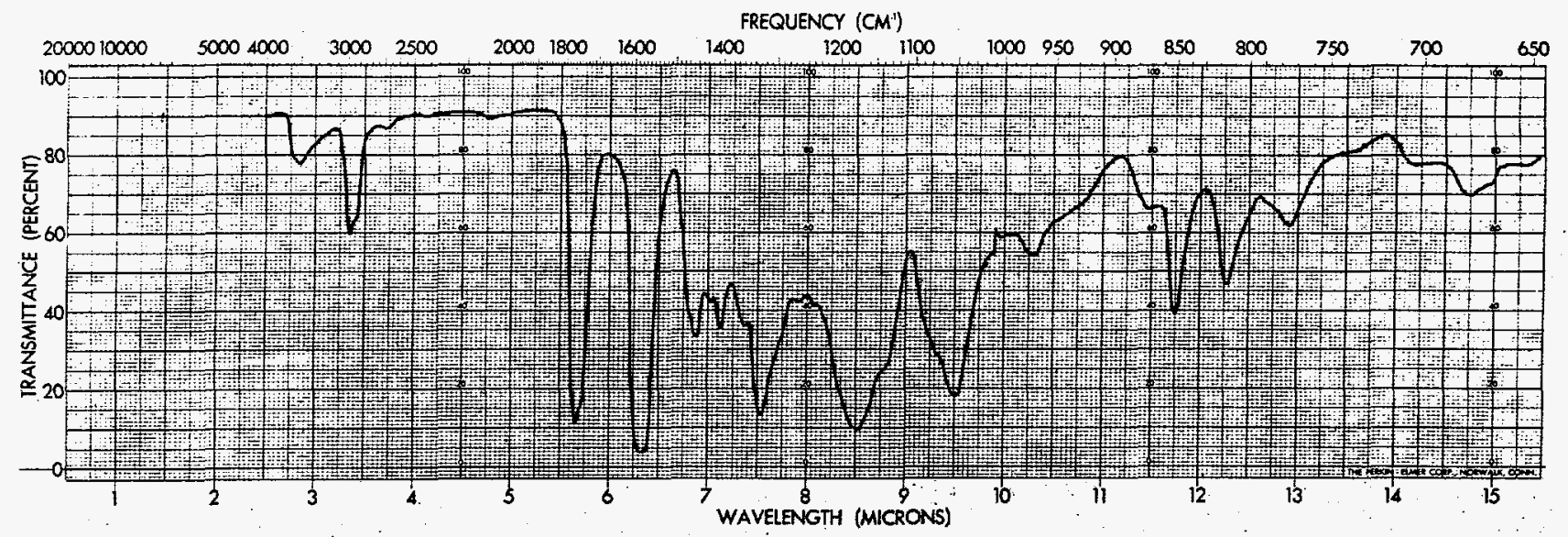

Fig. 24. IR-2nd Esterification Product Batch No. 2

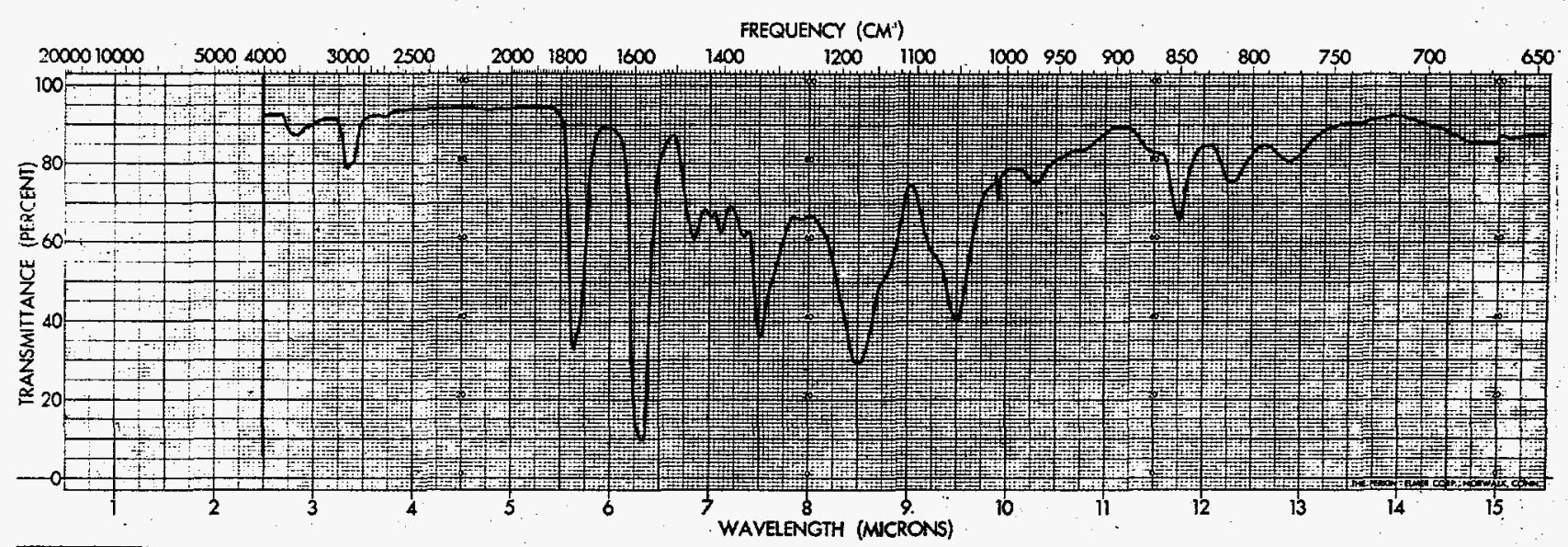

Fig. 25. IR-2nd Esterification Product Batch No. 3 


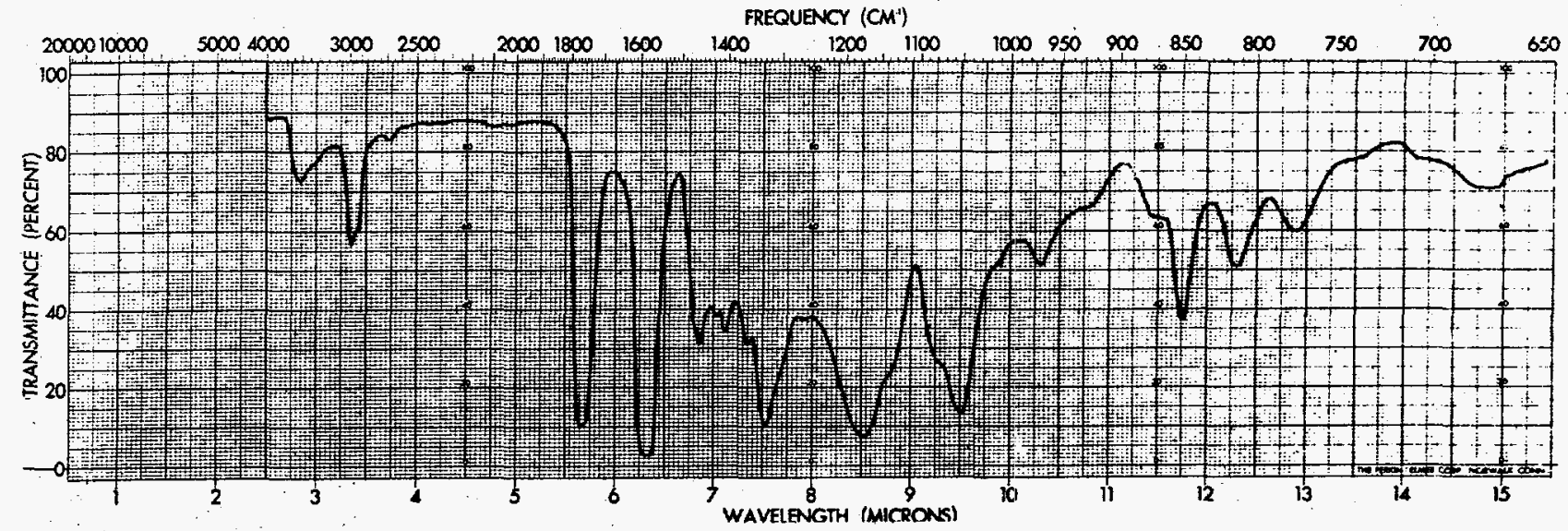

Fig. 26. IR-2nd Esterification Product Batch No. 4

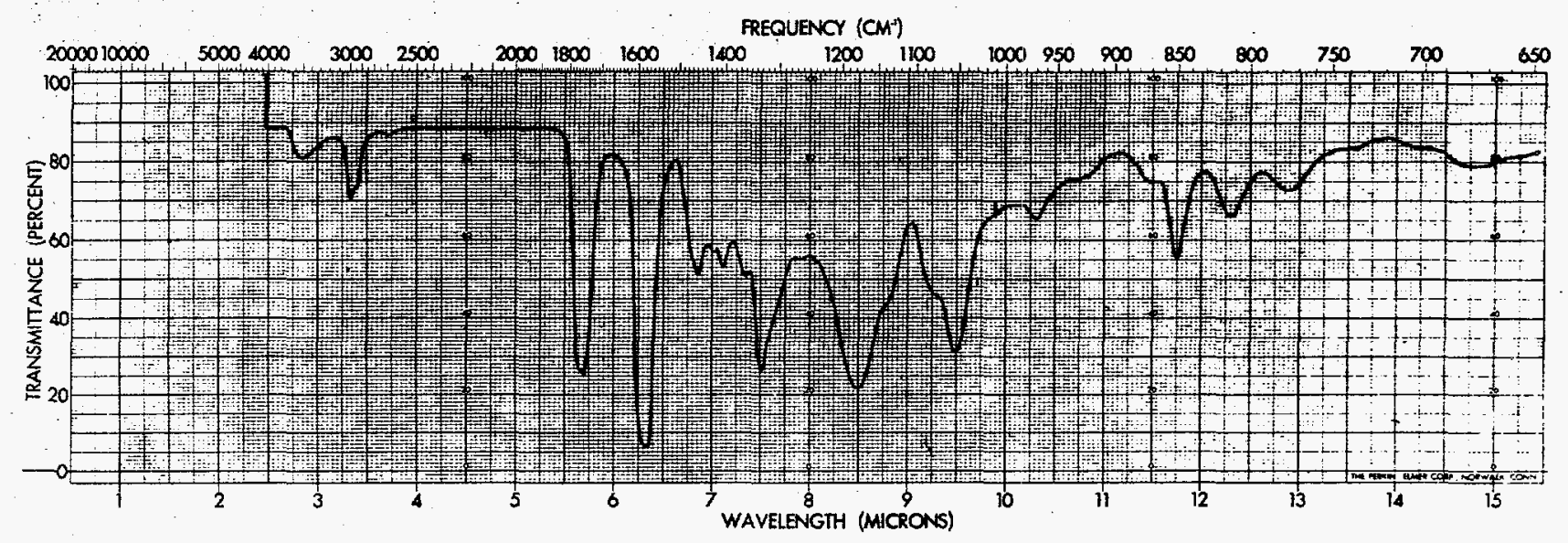

Fig. 27. IR-2nd Esterification Product Batch No. 5 



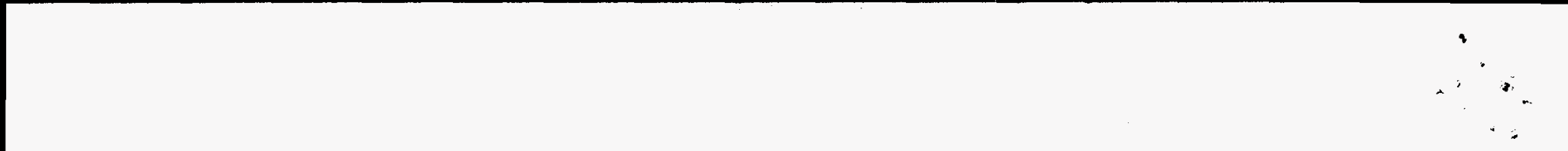

